\title{
Changes in the acid glycosaminoglycan content of the matrix of ageing human articular cartilage
}

\author{
R. A. STOCKWELL \\ Department of Anatomy, University Medical School, Edinburgh
}

Early chemical studies of the glycosaminoglycans of cartilage matrix (Kuhn and Leppelmann, 1958; Kaplan and Meyer, 1959) indicated an increasing content of keratansulphate with maturation and ageing, particularly when considered in relation to the total quantity of mucopolysaccharide. Subsequently, the general distribution of chondroitin sulphate and keratansulphate within the matrix were demonstrated by histochemical means (Stockwell and Scott, 1965; Scott and Stockwell, 1966). Quantitative evidence was later presented supporting the histochemical results in human articular cartilage (Stockwell and Scott, 1967; Maroudas, Muir and Wingham, 1969). Investigation has now been extended to a larger series of cases; this has revealed the presence, within the superficial zone of adult articular cartilage, of glycosaminoglycan material not observed previously. It is believed that this finding is relevant to the study of ageing and degeneration in synovial joints.

\section{Material and methods}

MATERIAL

Sixty specimens of human femoral condylar cartilage were examined, the ages of the subjects ranging from birth to 78 years. Fifty cases were obtained post mortem and ten at amputation or surgical exploration of the joint. Many joints examined were macroscopically normal.

\section{METHODS}

Joint surfaces were wiped gently with saline-moistened cotton wool before the tissue was excised. Cartilage from 56 cases was examined histochemically. Full-thickness blocks were taken from areas free of miacroscopic lesions. These were fixed in neutral 10 per cent. formalin for 24 hours and $10 \mu \mathrm{m}$. frozen sections were cut at $-25^{\circ} \mathrm{C}$. in a cryostat. Sections were stained using the following techniques.

(1a) Alcian blue, $8 \mathrm{GX} 0.05$ per cent. in $0.05 \mathrm{M}$ acetate buffer pH $5 \cdot 8$ containing $0 \cdot 4 \mathrm{M}$ magnesium chloride (AB-0.4M $\mathrm{MgCl}_{2}$ ) for $18 \mathrm{hrs}$ at room temperature (Scott and Dorling, 1965).

(1b) As for (a) but with $0.9 \mathrm{M}$ instead of $0.4 \mathrm{M}$ magnesium chloride (AB-0.9M MgCl 2 ).

(2) Azur A, 0.1 per cent., pH 5.8 for $30 \mathrm{~min}$.

(3) Azur $\mathrm{A}, 0.1$ per cent., adjusted to $\mathrm{pH} 0.7$ with hydrochloric acid for $30 \mathrm{~min}$.

(4) Toluidine blue, $0 \cdot 1$ per cent. for $30 \mathrm{~min}$.

(5) Periodic acid-Schiff (PAS) reaction (Pearse, 1968), before and after digestion with salivary amylase.

(6) Two-stage PAS reaction (for chondroitin sulphate) (Scott and Dorling, 1969).

(7) Sudan black B in propylene glycol (Pearse, 1968).

(8) Haematoxylin and eosin.

Cationic dye staining and PAS reactions were also performed after digestion with testicular hyaluronidase and, in some cases, after extraction with pyridine or $2: 1$ chloroform/methanol at $60^{\circ} \mathrm{C}$. for 24 hours. After staining, sections were examined microscopically in a thin film of the staining solution, before rinsing with water, etc. Thereafter sections were blotted dry, and taken through 96 per cent. and 100 per cent. alcohol and xylol, to mount in DePeX. The results given are based primarily on observations in the aqueous medium.

Cartilage from 36 cases was sampled for quantitative analysis. Where available, thin tangential slices of the superficial $0.25 \mathrm{~mm}$. of the tissue were taken from articular areas adjacent to that taken for histochemistry. Duplicate portions of tissue (2 to $5 \mathrm{mg}$. dry weight) were digested at $65^{\circ} \mathrm{C}$. with papain and polyanionic material precipitated with 1 per cent. cetyl pyridinium chloride (CPC) at $0.35 \mathrm{M}$ sodium chloride (Scott, 1960). The CPC complex was dissociated with $2 \mathrm{M}$ sodium chloride and CPC removed with chloroform. Uronic acid was determined by the borate modification of the carbazole method (Gregory, 1960) using glucuronolactone as standard. Hexose was estimated using the cysteinesulphuric acid method (Dische, 1955) with galactose as standard. The deep matrix within $0.25 \mathrm{~mm}$. of the calcified layer was similarly examined; in the case of newborn tissue, epiphyseal cartilage was taken at a depth of at least $2 \mathrm{~mm}$. from the articular surface. 


\section{Results}

\section{Quantitative analysis}

In both superficial and deep zones, the concentration of uronic acid (indicating chondroitin sulphate content) falls rapidly during early maturation (Table I). In the superficial zone, a similar though less pronounced diminution occurs in the values for hexose (reflecting keratansulphate); in the deep zone, the mean value for hexose in the 23 adult cases is higher than in the younger cases, but there is considerable variation in the adult group. In neither zone is there evidence of an age-related change in the values for uronic acid or hexose after the third decade.

A graph of the values for the ratio : hexose/hexose + uronic acid is shown in Fig. 1. At birth the ratio

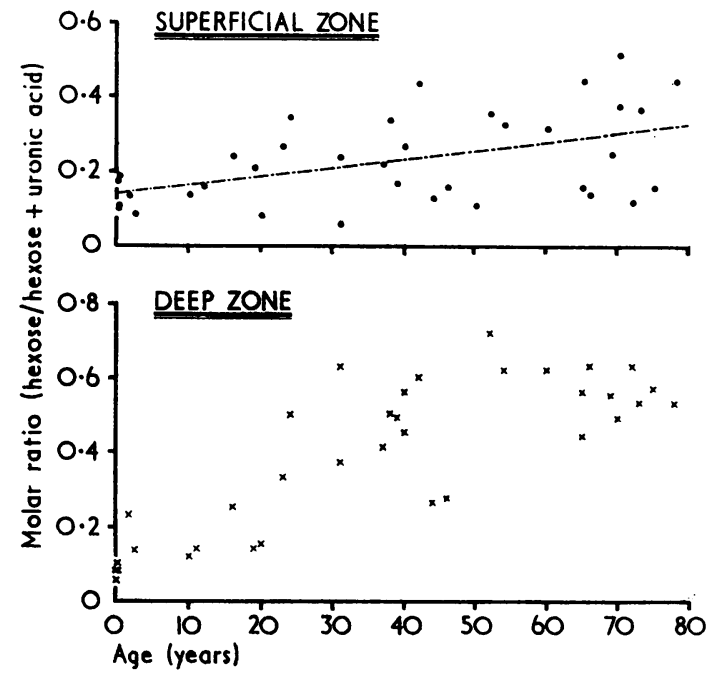

FIG. 1 Changes with age in proportions of acid glycosaminoglycans in human femoral condylar cartilage is approximately the same in both zones. In the superficial zone there appears to be a steady increase in the ratio during the whole life-span and the regression line is shown $(y=0.141+0.00235 x ; \mathrm{t}=$ $3 \cdot 3 ; \mathbf{P}<0.01$ ). If the adult period of life is considered separately, however, the apparent increase seen is not significantly different from zero. In the deep zone the ratio remains low until the third decade, when there appears to be a sharp rise to reach a plateau at the end of the fourth decade. During the period 0 to 20 years the mean value of the ratio is significantly lower than for the period 31 to 78 years $(0.12 \pm 0.06 ; n=11$ and $0.52 \pm$ $0 \cdot 12 ; \mathrm{n}=18 ; \mathrm{P}<0.001)$.

\section{Histochemical techniques}

Results with azur A, toluidine blue, and haematoxylin and eosin are approximately the same as with AB-0.4M $\mathrm{MgCl}_{2}$. Immature specimens are intensely and uniformly stained with $\mathrm{AB}-0.4 \mathrm{M} \mathrm{MgCl}{ }_{2}$, which demonstrates both chondroitin sulphate and keratansulphate. AB-0.9M $\mathrm{MgCl}_{2}$, for high molecular weight keratansulphate, gives either a very weak reaction or none. During maturation and in fully developed cartilage this uniform distribution changes to a predominantly pericellular (territorial) pattern with $\mathrm{AB}-0.4 \mathrm{M} \mathrm{MgCl} 2$, while with $\mathrm{AB}-0.9 \mathrm{M} \mathrm{MgCl}_{2}$ staining is rather less intense and lies in the interterritorial region (Fig. $2 a-c$ ). With the latter technique, however, the pericellular regions are stained in the deep matrix adjacent to the calcified layer in cases aged about 40 years and over (Fig. $2 b$ ).

The two PAS techniques result in inverse patterns of dye distribution in adult cartilage. The routine PAS reaction (Fig. $2 d, 3 a$ ) stains the interterritorial regions while the two-stage PAS method (Fig. $2 e$, $3 b)$ gives intense pericellular staining, with much less

Table I Analysis of uronic acid and hexose content of human articular cartilage (as per cent. dry weight of tissue)

\begin{tabular}{|c|c|c|c|c|}
\hline \multirow{2}{*}{$\begin{array}{l}\text { Age } \\
(y r s)\end{array}$} & \multicolumn{2}{|c|}{ Superficial zone } & \multicolumn{2}{|l|}{ Deep zone } \\
\hline & $\begin{array}{l}\text { Uronic acid } \\
\text { (as lactone) }\end{array}$ & $\begin{array}{l}\text { Hexose } \\
\text { (as galactose) }\end{array}$ & $\begin{array}{l}\text { Uronic acid } \\
\text { (as lactone) }\end{array}$ & $\begin{array}{l}\text { Hexose } \\
\text { (as galactose) }\end{array}$ \\
\hline $\begin{array}{l}\text { Newborn (4 cases) } \\
20 \text { mths } \\
29 \text { mths } \\
10 \\
11 \\
16 \\
19 \\
20 \\
23 \\
24 \\
31-78 \text { (23 cases)* }\end{array}$ & $\begin{array}{l}4 \cdot 23-5 \cdot 75 \\
2 \cdot 81 \\
1 \cdot 38 \\
2.05 \\
1 \cdot 81 \\
0 \cdot 52 \\
0.95 \\
0.90 \\
0.36 \\
1 \cdot 72 \\
0.83 \pm 0.38\end{array}$ & $\begin{array}{l}0.48-1 \cdot 28 \\
0 \cdot 44 \\
0 \cdot 13 \\
0.33 \\
0.35 \\
0.17 \\
0.26 \\
0.08 \\
0.13 \\
0.76 \\
0.33 \pm 0.22\end{array}$ & $\begin{array}{l}7 \cdot 16-10 \cdot 69 \\
3 \cdot 29 \\
7 \cdot 28 \\
3 \cdot 58 \\
3 \cdot 51 \\
1.36 \\
1.71 \\
0.99 \\
1.47 \\
1 \cdot 11 \\
0.97 \pm 0.40\end{array}$ & $\begin{array}{l}0.59-1 \cdot 00 \\
1.01 \\
1 \cdot 16 \\
0.50 \\
0.57 \\
0.47 \\
0.28 \\
0.18 \\
0.75 \\
1 \cdot 15 \\
1 \cdot 15 \pm 0.72\end{array}$ \\
\hline
\end{tabular}

- Mean values \pm 1 standard deviation 

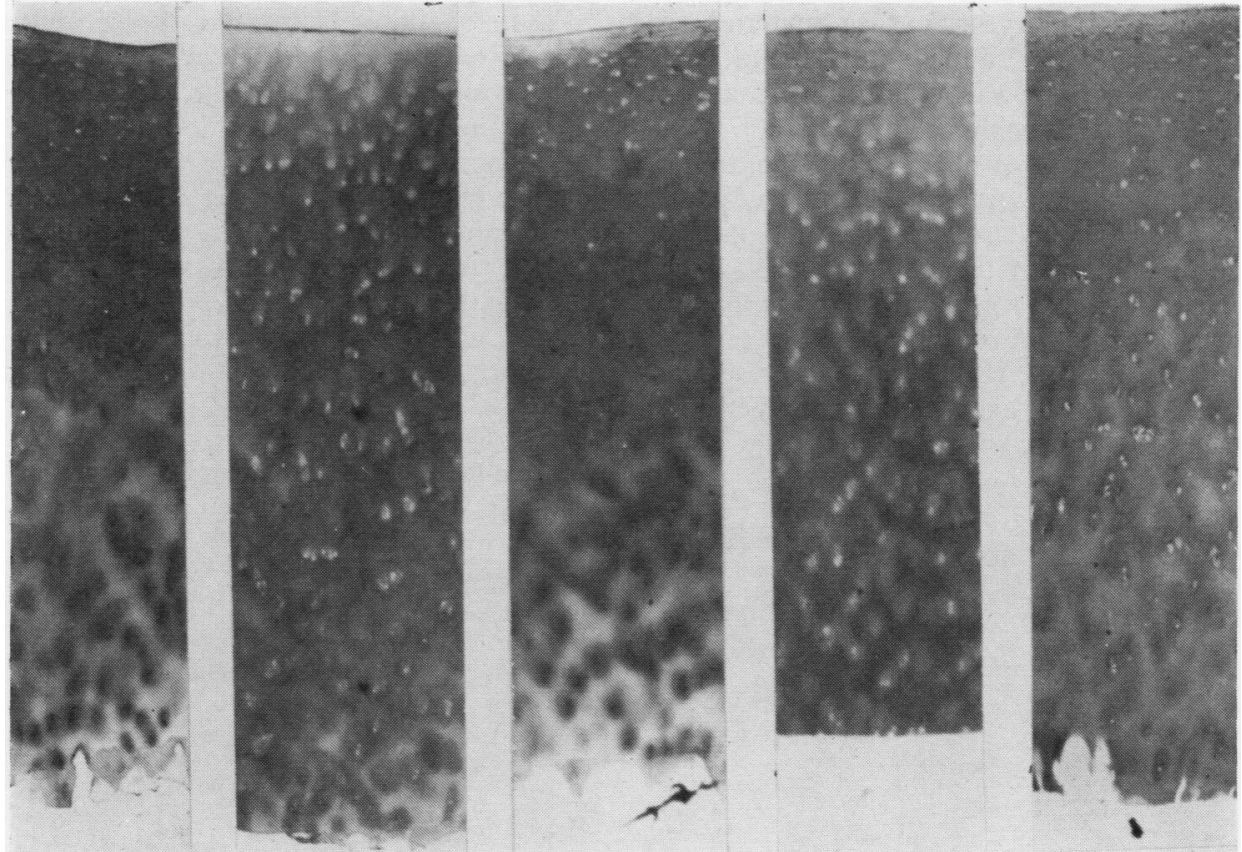
(a) $\mathrm{AB}-0 \cdot 4 \mathrm{M} \mathrm{MgCl}$
(b) $A B-0.9 M \mathrm{MgCl}_{2}$
(c) Toluidine blue
(d) Routine PAS
(e) Two-stage PAS

FIG. 2 Human femoral condylar cartilage, aged 73 years. $\times 27$

colour intensity interterritorially. In mature tissue, Sudan black B colours the matrix in the superficial zone thus demonstrating the presence of lipid; although the majority of cases give this result, there is considerable variation between specimens as to the concentration of lipid and the thickness of the zone in which it lies. Pericellular deposits of lipid are maximal in the region subjacent to the superficial zone.

\section{Surface lamina}

With both Alcian blue techniques, staining of the superficial quarter of the cartilage thickness in adult cases is considerably less intense than in the middle part of the tissue; in many cases it is hardly stained with $\mathrm{Ab}-0.9 \mathrm{M} \mathrm{MgCl}$. However the reaction of the most superficial lamina of the matrix (within about $5 \mu \mathrm{m}$. of the articular surface) to $\mathrm{AB}-0.9 \mathrm{M} \mathrm{MgCl}$ is extremely variable. In many specimens especially the young adult and the immature, staining is almost completely absent (Fig. 4a), while in some older cases a continuous lamina of alcianophilic material can be demonstrated (Fig. 4b). Both the thickness and the degree of continuity of this stained lamina vary, some positive surfaces showing only small patches $1 \mu \mathrm{m}$. or less thick. This Alcian bluepositive material lies superficial to the diffuse lipid of the superficial zone when both types of substance are present in the same tissue.

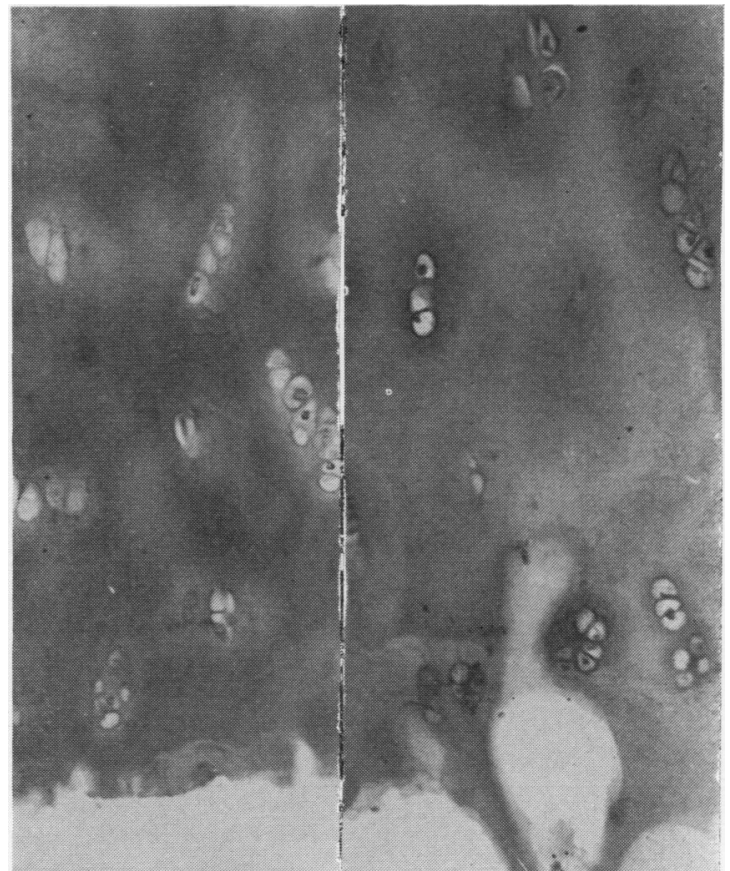

(a) Routine PAS-interterritorial staining

(b) Two-stage PAS-pericellular staining predominates

FIG. 3 Deep zone, femoral condylar cartilage, aged 73 years. $\times 150$ 
Staining properties of the surface material are illustrated in Figs 4 and 5 and summarized in Table II. Dye binding at high salt concentration and at low pH suggests that the enhancement of stain is due principally to the presence of an acid glycosaminoglycan with properties similar to keratansulphate. Resistance to hyaluronidase digestion and lack of stain intensification with the two-stage PAS technique (probably specific for chondroitin sulphate in cartilage) lend weight to this conclusion. The positive reaction to the routine PAS technique suggests that glycoprotein is present also. Some specimens exhibited a lamina positive with $\mathrm{AB}-0.4 \mathrm{M} \mathrm{MgCl}$, but not with $\mathrm{AB}-0.9 \mathrm{M} \mathrm{MgCl}_{2}$.
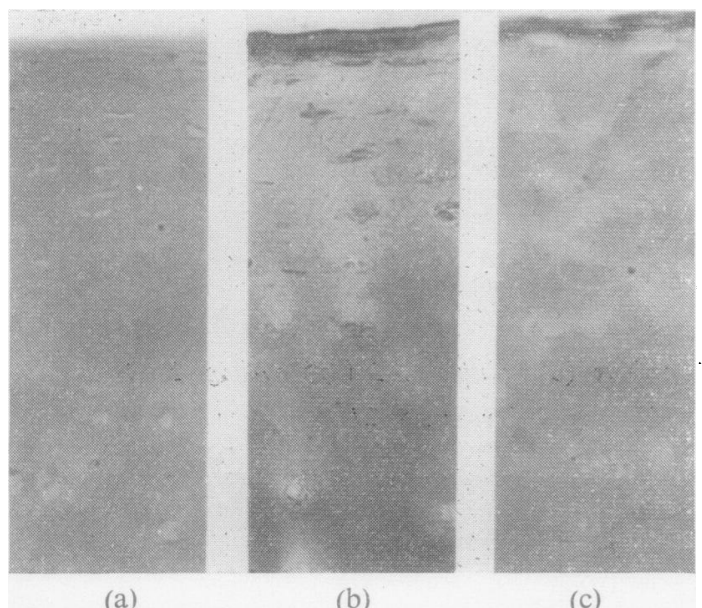

FIG. 4 Surface lamina, human articular cartilage (aqueous mounts). $\times 110$

(a) Aged 20, $A B-0.9 M \mathrm{MgCl}_{2}$. No surface staining.

(b) Aged 73, $\mathrm{AB}-0.9 \mathrm{M} \mathrm{MgCl}$

(c) Serial section with (b), azur A pH 0.7 after 20 hrs' hyaluronidase

Table II Staining of Alcianophilic (0.9M $\left.\mathrm{MgCl}_{2}\right)$ material in surface lamina of human articular cartilage

\begin{tabular}{|c|c|c|}
\hline Technique & Result & Conclusion \\
\hline Toluidine blue &,+ B metachromatic & $\begin{array}{l}\text { Anionic } \\
\text { Probably sulphated }\end{array}$ \\
\hline $\begin{array}{r}\text { Azur A pH } 5.8 \\
\text { pH } 0.7\end{array}$ & + & $\begin{array}{l}\text { Anionic } \\
\text { Sulphated }\end{array}$ \\
\hline $\begin{array}{r}\mathrm{AB}-0.4 \mathrm{M} \mathrm{MgCl} \\
0.9 \mathrm{M} \mathrm{MgCl}\end{array}$ & $\begin{array}{l}+ \\
+\end{array}$ & $\begin{array}{l}\text { Polyanion with sulphate and carboxyl } \\
\text { groups present and/or polyanion with } \\
\text { sulphate groups only } \\
\text { Polyanion with sulphate groups only }\end{array}$ \\
\hline $\begin{array}{c}\text { Periodic acid-Schiff Two-stage } \\
\text { Routine }\end{array}$ & $\overline{ \pm}$ & $\begin{array}{l}\text { Little or no chondroitin sulphate } \\
\text { Some glycoprotein present }\end{array}$ \\
\hline Testicular hyaluronidase & Resistant & $\begin{array}{l}\text { Probably not chondroitin sulphate or } \\
\text { hyaluronic acid }\end{array}$ \\
\hline $\begin{array}{l}\text { Pyridine or chloroform/methanol } \\
\text { extraction }\end{array}$ & Resistant & $\begin{array}{l}\text { Probably not lipid (diffuse lipid in } \\
\text { superficial zone is removed) }\end{array}$ \\
\hline
\end{tabular}

Where available, values for the concentration of hexose (related to the keratansulphate fraction of the glycosaminoglycans) in the superficial $0.25 \mathrm{~mm}$. of positive specimens (exhibiting the AB-0.9M $\mathrm{MgCl}_{2}$-positive lamina) have been compared with negative samples, in cases aged 30 years and over. The mean value is higher in the positive $(0.36 \pm$ 0.22 per cent. dry weight tissue; $n=12$ ) than in the negative group $(0 \cdot 20 \pm 0 \cdot 10$ per cent. dry weight; $n=8$ ), although the difference between the means is not quite significant at the 5 per cent. level $(\mathrm{t}=1 \cdot 88 ; 0.1>\mathrm{P}>0.05)$.

\section{Relation to Age and Cartilage Degeneration}

Material stained with $\mathrm{AB}-0.9 \mathrm{M} \mathrm{MgCl}{ }_{2}$ in the surface

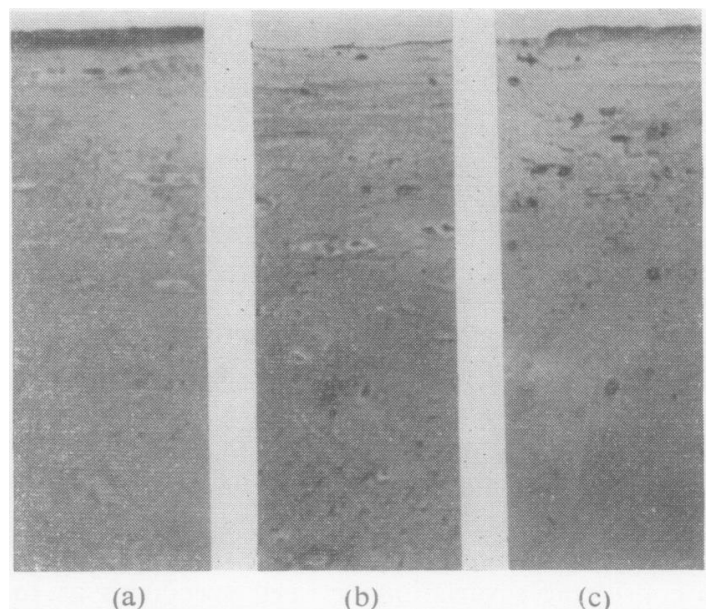

FIG. 5 Surface lamina, human articular cartilage, aged 39 years (aqueous mounts). $\times 120$

(a) $\mathrm{AB}-0.9 \mathrm{M} \mathrm{MgCl}$

(b) Two-stage PAS. No staining of surface lamina

(c) Routine PAS 
lamina is seen with increasing frequency with advancing age (Table III). It is not observed in cases aged 20 years or less and is present in a majority after the fourth decade. As regards cartilage degeneration, the material is usually present in macroscopically normal surfaces adjacent to areas showing minimal fibrillation or ulceration.

Table III Alcianophilic (0.9M $\left.\mathrm{MgCl}_{2}\right)$ material in surface lamina of human articular cartilage, by age.

Figures in parentheses indicate number of cases with visible erosions of articular cartilage.

\begin{tabular}{lll}
\hline Age group (yrs) & Present & Absent \\
\cline { 1 - 1 } \cline { 3 - 3 } $0-3$ & 0 & 8 \\
$10-20$ & 0 & 6 \\
$21-40$ & 1 & 10 \\
$41-60$ & 6 & $7(1)$ \\
$61-80$ & $13(4)$ & $5(2)$ \\
\hline
\end{tabular}

However the majority of positive specimens are taken from joints showing no obvious lesion. In these cases, aged 30 years and over, features such as basophilic 'rimming' of the rounded cells in the transitional layer, and roughness of the articular surface, are more common in specimens which contain the surface material. To provide a more objective assessment, nuclear counts have been made in the superficial $0.12 \mathrm{~mm}$. of the articular cartilage. These are significantly lower in the positively-stained group than in the negative cases $(438 \pm 103$ nuclei per sq. $\mathrm{mm} . ; \mathrm{n}=15$ and $676 \pm 91$ nuclei per sq. $\mathrm{mm} . ; \mathrm{n}=12 ; \mathrm{t}=6.03, \mathrm{P}<0.001$ ). Cases showing staining of the surface lamina with $\mathrm{AB}-0 \cdot 4 \mathrm{M} \mathrm{MgCl}_{2}$ but not AB-0.9M $\mathrm{MgCl}_{2}$ are not included.

\section{Discussion}

Absolute values of hexose and uronic acid concentrations given in this study should be accepted with some caution in view of the small quantities of tissue analysed. Difficulties inherent in extrapolating from data based on these components of the glycosaminoglycans to the polyanions themselves have been discussed previously (Stockwell and Scoti, 1967). In general, this can be done with more confidence in the case of uronic acid and chondroitin sulphate, than with hexose and keratansulphate. However, the results in general agree with those of other workers. Thus the concentrations of hexose and uronic acid in both superficial and deep zones show the trend noted by others (Kuhn and Leppelmann, 1958; Kaplan and Meyer, 1959) during maturation and ageing, and the values are approximately the same, in adults, as those given by Bollet and Nance (1966). The development in adult life in the deep zone of a plateau for the ratio : hexose/ hexose + uronic acid also agrees with similar findings in human costal cartilage (Mathews and Glagov, 1966). It is interesting that the value of this ratio rises steeply in the deep zone during the period following epiphyseal closure. The change in the proportions of the two glycosaminoglycans which this indicates may be related to differences in the sources of nutrition of articular cartilage during the immature and adult periods. In the adult, supply from the marrow spaces in the subchondral bone is reduced (McKibbin and Holdsworth, 1968) while permeability studies reveal little or no penetration through the basal calcified cartilage and bone (Maroudas, Bullough, Swanson, and Freeman, 1968). Experimental results thus suggest that nutritional conditions are poor in the deep zone. It has been suggested (Stockwell and Scott, 1965) that the pericellular localization of keratansulphate demonstrated histochemically in the deep zone in adult cartilage may be related to this factor.

Results with Alcian blue and the other cationic dyes agree with previous observations. In adult cartilage, high molecular weight keratansulphate (AB-0.9 $\mathrm{M} \mathrm{MgCl}_{2}$ ) is localized interterritorially (in most of the thickness of the cartilage), while chondroitin sulphate is most abundant in pericellular sites. The two-stage PAS technique (Scott and Dorling, 1969) offers a highly specific second method for the localisation of chondroitin sulphate in human cartilage. Results with this method demonstrate a diffuse distribution throughout the matrix, but with much greater staining intensity near the cells. This agrees with the findings in horse nasal cartilage (Scott and Dorling, 1969) and confirms previous observations in human articular cartilage.

The variable incidence and minimal dimensions of the surface lamina stained by $\mathrm{AB}-0.9 \mathrm{M} \mathrm{MgCl}_{2}$ and by other techniques raise the possibility that it may be an artefact of some kind. However, it is too thick in many cases to be dismissed as an optical refractile effect, although it verges onto the articular surface. Drying and compaction at the cartilage surface might produce enhancement of staining, but exposure of specimens to drying in air at room temperature for 1 hour before fixation does not yield positive results in specimens found to be negative by the routine procedure. Again, superficial staining with Alcian blue is not attributable specifically to post mortem effects, for it is present in specimens obtained at operation or from amputated limbs as well as in post mortem tissue. Earlier investigations using Alcian blue at different salt concentrations did not reveal the presence of the surface staining (Stockwell and Scott, 1965), for the number of cases in the appropriate age group was small and they were macroscopically normal. Staining of the surface material is extremely faint with haematoxylin and eosin, and dyes such as toluidine blue and azur A do not give so intense a colour as Alcian blue. This is probably relevant to previous histological investigations of articular cartilage. Studies on 
ageing and pathology of articular cartilage have been concerned more with the loss of metachromasia and basophilia rather than its increase. Thus thin surface laminae of toluidine blue-positive staining (Meachim, Ghadially, and Collins, 1965; Figs 3 and 5) apparently have not drawn comment although similar material may be involved to that reported in the present study. It is emphasized that the AB-09M $\mathrm{MgCl}_{2}$-stained material in the surface of mature cartilage represents an additional feature, at least as regards staining reaction, as compared with immature and young adult cartilage surfaces where there is virtually no reaction with this technique.

Immunofluorescent work on porcine articular cartilage shows some correlation with the present study. Loewi (1965), treating sections of pig cartilage with fluorescein-conjugated antibody to chondromucoprotein, noted a similar lamina of fluorescence at the articular surface. Although adjacent sections had been stained with $\mathrm{AB}-0 \cdot 5 \mathrm{M} \mathrm{MgCl}_{2}$, results obtained at the surface with this technique are not reported.

Using bovine cartilage, Balazs, Bloom, and Swann (1966) detected amorphous or fine filamentous material with the electron microscope, in a layer about $1 \mu \mathrm{m}$. thick on the articular surface. The amount increased during maturation and ageing. Analysis of fluid and tissue aspirated and scraped from the unwashed surface indicated that a major constituent of the substances thus obtained was hyaluronic acid. In adult human articular cartilage also, electron-dense amorphous areas of the matrix may be found near the joint surface (Meachim and Roy, 1969). These are similar in appearance to the bovine surface aggregates but may be separated from the joint surface by collagen fibrils. Although there is some correlation between the position of the ultrastructural amorphous substance and AB-0.9M $\mathrm{MgCl}_{2}$ stain distribution in $1 \mu \mathrm{m}$. thick araldite sections of bulk-stained human articular cartilage (Stockwell, unpublished), the histochemical properties do not suggest that it is hyaluronate.

It would be unwise to attempt to identify the polyanionic material at the surface purely on histochemical findings. The results suggest, however, the presence of a sulphated glycosaminoglycan of the keratansulphate type, together with some glycoprotein. On this evidence, therefore, it might be expected that hexose concentrations would be higher in the superficial zone samples of positive than of negative cases. There is some suggestion of this in the figures obtained. The lack of statistical confirmation for a difference between the means of the two groups seems due chiefly to a large variation in the values for the positive group. This parallels the variability in the staining of the different cartilage specimens to some extent. Furthermore, the analytical results are for the superficial $0.250 \mathrm{~mm}$. of the tissue, while the stained lamina occupies at most only the superficial $0.005 \mathrm{~mm}$. More sensitive methods of analysis are needed on samples of cartilage taken from regions that correspond more closely with the extent of the alcianophilic material. A better correlation between quantitative and qualitative methods may then be achieved.

The question arises whether the surface glycosaminoglycan is present in the tissue during youth, subsequently becoming 'unmasked' and stainable, or whether material is added to the tissue during maturity. Origins from the synovial fluid, from the chondrocytes, or from the matrix may all be considered. In the latter case, it is noteworthy that faint staining with $\mathrm{AB}$ at $0.9 \mathrm{M}$ and higher concentrations of $\mathrm{MgCl}_{2}$ occurs in newborn tissue in areas where collagen fibres are abundant (Scott and Dorling, 1965). It has been demonstrated that the most superficial part of young adult human articular cartilage contains a high density of collagen fibrils (Weiss, Rosenberg, and Helfet, 1968). In view of the virtual absence of staining with $\mathrm{AB}-0.9 \mathrm{M} \mathrm{MgCl}_{2}$ at the surface of young adult cartilage, it is unlikely that the alcianophilic lamina present in older specimens is due solely to the presence of collagen. However, it may be speculated that such staining might be associated with the disruption of a collagenprotein-polysaccharide complex.

The increasing incidence of surface alcianophilia with age occurs in apparently normal joints, but this does not rule out the possibility of pathology. On the evidence of this study, cartilage surfaces which exhibit this material also have a diminished cell density, together with basophilic rimming of the rounded cells of the subjacent transitional layer. These two features, among others, are cited as early regressive changes in articular cartilage (Meachim, Ghadially, and Collins, 1965; Meachim and Roy, 1969). It is suggested, therefore, that the present finding should be placed in the same category. This does not mean that the material is necessarily causal with respect to cartilage degeneration, although it is possible that changes in properties such as permeability and resilience of the tissue believed to be related to its mucopolysaccharide content, could result from its presence. Such effects could be damaging to the tissue locally. While such early regressive changes appear to be clinically asymptomatic, their contribution, if any, to the initiation of osteoarthrosis should be given consideration. With respect to the surface alcianophilia, however, the number of cases is small as yet, and further studies are needed before firm conclusions as to its significance can be made. 


\section{Summary}

The glycosaminoglycans of human femoral condylar articular cartilage have teen investigated quantitatively and histochemically in specimens from birth to 78 years.

In ageing macroscopically normal cartilage, material stained with Alcian blue (in the presence of $0.9 \mathrm{M} \mathrm{MgCl}_{2}$ ) is found in a lamina within $5 \mu \mathrm{m}$. of the articular surface. This is variable in its incidence and in amount, but is found in a majority of cases aged over 40 years. From its histochemical properties, the material contains a glycosaminoglycan similar to keratansulphate together with glycoprotein. The presence of this material is associated with a reduced number of cells in the superficial zone of the cartilage; it is suggested that this alcianophilic layer constitutes a regressive change.

In the deep (non-calcified) layer of the tissue, analysis of hexose and uronic acid indicates an increase in the proportion of keratansulphate to keratansulphate plus chondroitin sulphate, during the third and fourth decades only. During this period the distribution of keratansulphate as demonstrated with Alcian blue $\left(0.9 \mathrm{M} \mathrm{MgCl}_{2}\right)$ becomes pericellular rather than interterritorial. It is suggested that these observations may be related to changes in the sources of nutrition of the tissue said to occur at maturation.

The use of the two-stage PAS technique for chondroitin sulphate confirms the distribution of this substance as demonstrated with Alcian blue at various salt concentrations.

I am most grateful to Dr. J. E. Scott and Prof. G. J. Romanes for reading the text and for their helpful suggestions. I thank Messrs. H. Tully and T. M. Paterson for the photomicrography, and Miss S. Fowler for secretarial assistance. I am indebted to members of the surgical staff of St. Thomas's Hospital, London, and the Princess Margaret Rose Hospital, Edinburgh, and to Prof. G. Montgomery for access to material.

\section{References}

Balazs, E. A., Bloom, G. D., and Swann, D. A. (1966) Fed. Proc., 25, 1813 (Fine structure and glycosaminoglycan content of the surface layer of articular cartilage).

Bollet, A. J., AND NANCE, J. L. (1966) J. clin. Invest., 45, 1170 (Biochemical findings in normal and osteoarthritic articular cartilage. II. Chondroitin sulfate concentration and chain length, water, and ash content).

Dische, Z., (1955) Meth. biochem. Anal., 2, 313 (New color reactions for determination of sugars in polysaccharides).

Gregory, J. D. (1960) Arch. Biochem. Biophys., 89, 157 (The effect of borate on the carbazole reaction).

KAPLAN, D., AND MEYeR, K. (1959) Nature (Lond.)., 183, 1267 (Ageing of human cartilage).

Kuhn, R., ANd LeppelmanN, H. J. (1958) Justus Liebigs Ann. Chem., 611, 254 (Galaktosamin und Glucosamin im Knorpel in Abhängigkeit vom Lebensalter).

LOEWI, G. (1965) Ann. rheum. Dis., 24, 528 (Localization of chondromucoprotein in cartilage).

McKibin, B., AND HoldsworTh, F. (1968) J. Bone Jt Surg., 50B, 876 (The source of nutrition of articular cartilage).

Maroudas, A., Bullough, P., Swanson, S. A. V., and Freeman, M. A. R. (1968) Ibid., 50B, 166 (The permeability of articular cartilage).

- Muir, H., AND Wingham, J. (1969) Biochim. biophys. Acta, 177, 492 (The correlation of fixed negative charge with glycosaminoglycan content of human articular cartilage).

Mathews, M. B., AND GlaGov, S. (1966) J. clin. Invest., 45, 1103 (Acid mucopolysaccharide patterns in aging human cartilage).

Meachim, G., Ghadially, F. N., and Collins, D. H. (1965) Ann. rheum. Dis., 24, 23 (Regressive changes in the superficial layer of human articular cartilage).

— AND Roy, S. (1969) J. Bone Jt Surg., 51B, 529 (Surface ultrastructure of mature a dult human articular cartilage).

Pearse, A. G. E. (1968) 'Histochemistry: Theoretical and Applied', 3rd ed. Churchill, London.

ScotT, J. E. (1960) Meth. biochem. Anal., 8, 145 (Aliphatic ammonium salts in the assay of acidic polysaccharides from tissues).

- AND Dorling, J. (1965) Histochemie, 5, 221 (Differential staining of acid glycosaminoglycans (mucopolysaccharides) by Alcian Blue in salt solutions).

— - (1969) Ibid., 19, 295 (Periodate oxidation of acid polysaccharides. III. A PAS method for chondroitin sulphates and other glycosamino-glycuronans).

- AND Stockwell, R. A. (1966) J. Histochem. Cytochem., 15, 111 (On the use and abuse of the critical electrolyte concentration approach to the localization of tissue polyanions).

Stockwell, R. A., AND Scott, J. E. (1965) Ann. rheum. Dis., 24, 341 (Observatinns on the acid glycosaminoglycan (mucopolysaccharide) content of the matrix of ageing cartilage).

- - - (1967) Nature (Lond.)., 215, 1376 (Distribution of acid glycosaminoglycans in human articular cartilage).

Weiss, C., Rosenberg, L., and Helfet, A. J. (1968) J. Bone Jt Surg., 50A, 663 (An ultrastructural study of normal young adult human articular cartilage). 